\title{
Foundation plate on the elastic half-space, deterministic and probabilistic approach
}

\author{
Katarina Tvrdá1,* \\ ${ }^{1}$ Slovak University of Technology, Faculty of Civil Engineering, Radlinského 11, 81005 Bratislava, \\ Slovakia
}

\begin{abstract}
Interaction between the foundation plate and subgrade can be described by different mathematical - physical model. Elastic foundation can be modelled by different types of models, e.g. one-parametric model, two-parametric model and a comprehensive model - Boussinesque (elastic half-space) had been used. The article deals with deterministic and probabilistic analysis of deflection of the foundation plate on the elastic half-space. Contact between the foundation plate and subsoil was modelled using contact elements node-node. At the end the obtained results are presented.
\end{abstract}

\section{Introduction}

Currently, the most widely used methods for the analysis of building structures are: finite element method (FEM), boundary element method and finite volumes method. Analytical solution of building structures gradually recedes. Most scientific as well as civil engineering software products are based on FEM deformation variant.

Each building structure is rested on the Earth's surface, so it is necessary to analyse these structures in interaction with subsoil. The subsoil represents in fact an infinite area which, however, in the final model has its limits. From the historical viewpoint, the most used model is the Winkler model. Later two-parametric models subsoil had been introduced, implementing the effect of shear forces and impact of subgrade around the foundation into the calculation. Other models are based on the theory of elastic half-space where the different types of subsoil are described by physical properties (elastic modulus, Poisson's ratio, density). Using FEM introduced a lot of advantages to modelling structures in the interaction with the subsoil. It allows the inhomogeneous subsoil (layered), anisotropy to be implemented into the calculation.

Recently, numerous authors have been dealing with the interaction of the subsoil with structures, whether in statics, dynamics, or deterministic and probabilistic analyses [1-4].

\section{The structure - subgrade interaction}

Inseparable part of the building structure is groundmass in which the structure is built. This

\footnotetext{
*Corresponding author: katarina.tvrda@stuba.sk
} 
massive area is infinite, but in modelling structures in the interaction with the subsoil it must have its limits. In modelling, it is important to choose the right mathematical physical model to describe the subsoil.

Elastic foundation can be modelled with these types of models:

- one-parametric model (Winkler),

- two-parametric model (Pasternak),

- elastic half-space model (Boussinesque).

The theory of continuous elastic half-space implies that the subgrade forms a continuous, homogeneous and perfectly elastic body of infinitely large size, limited from above by the plane on which lies the foundation structure. Sometimes it is referred to as the Boussinesque model of soil. The model is characterized by two physical constants derived from experimental measurements ( $E$ - modulus of elasticity and $v$ - Poisson constant). To solve contact problems (foundation - elastic half-space) numerical methods have been primarily used to appropriately extend the closed form solutions while offering the possibility of a more realistical capture the interaction characteristics with the subsoil building structure for different boundary conditions.

Elastic foundation is modelled by spatial (3D) finite elements. In modelling of elastic half-space it is necessary to create a sufficiently large volume of groundmass, which to some extent depends on supporting and the boundary conditions. For the analysis of interaction of the foundation with the subsoil (static bond on the contact surface), two basic models can be defined: computational model with bilateral bond - continuous model, and calculation model with unilateral bond - discrete model.

\section{Assessment of the reliability of structures}

Reliability can be defined as the probabilistic measure of assurance of performance with respect to some prescribed conditions (ultimate limit state or serviceability limit state). Reliability of the structures can be determined by probabilistic methods (Monte Carlo, Latin Hypercube Sampling, Stratified Sampling, Adaptive Sampling, Directional Sampling, Responce Surface Method and others). Most problems concerning the reliability of structures are defined by comparison of two stochastic values, loading effects $E$ and the resistance $R$, depending on the variable material and geometrics of the building structures. For such an assessment, performance criteria are first defined on the basis of functional relationship between the $n$-input variables, referred to as the basic random variables $X_{\mathrm{i}}$.

Reliability function $R F$, security, usability, reliability function reserves (1) can be generally expressed as a function of stochastic parameters $X_{1}, X_{2}, \ldots, X_{\mathrm{n}}$

$$
R F=g\left(X_{1}, X_{2}, \ldots, X_{\mathrm{n}}\right)
$$

where the functional dependence $\mathrm{g}\left(X_{1}, X_{2}, \ldots, X_{\mathrm{n}}\right)$ is a computing model (i.e. idealization of reality). The failure functions $g\left(X_{\mathrm{i}}\right)$ represent the condition of reliability (reserve) and can be expressed as a function of stochastic parameters. They may be defined as simple (e.g. for one section) or as complex structures, for more cross-sections (e.g. entire finite-element model). The probability of failure can be defined as:

$$
P_{f}=P[R<E]=P[(R-E)<0]
$$

where: $P_{f}$ is given by the general expression

$$
P_{f}=\iint_{\ldots} \iint_{g(X)<0} f_{X}\left(X_{1}, X_{2}, \ldots, X_{\mathrm{n}}\right) \mathrm{d} X_{1} \mathrm{~d} X_{2} \ldots \mathrm{d} X_{\mathrm{n}}
$$




\section{Foundation plate in interaction with the subsoil}

\subsection{Deterministic approach}

The analysed foundation plate is located under the residential building of the point type. It is made of concrete class C 25-30 with a thickness of $0.5 \mathrm{~m}$. The material properties are modulus of elasticity $E=31 \mathrm{GPa}$, Poisson's ratio of 0.2 . The subsoil consists of gravel G2 to a depth of 16.1 meters, then the rock continues. Standard gravel soil characteristics were taken, $E=180 \mathrm{MPa}, v=0.2$.

Dimensions of the foundation plate are $12 \times 12 \mathrm{~m}$. Groundmass is modelled in sufficient width, length and depth of $36 \times 36 \times 16.1$ meters. Loading of the foundation plate from the top of the building is in the point of columns, and it is calculated according to the relevant area and transfers application of load of eight floors (Fig. 1).

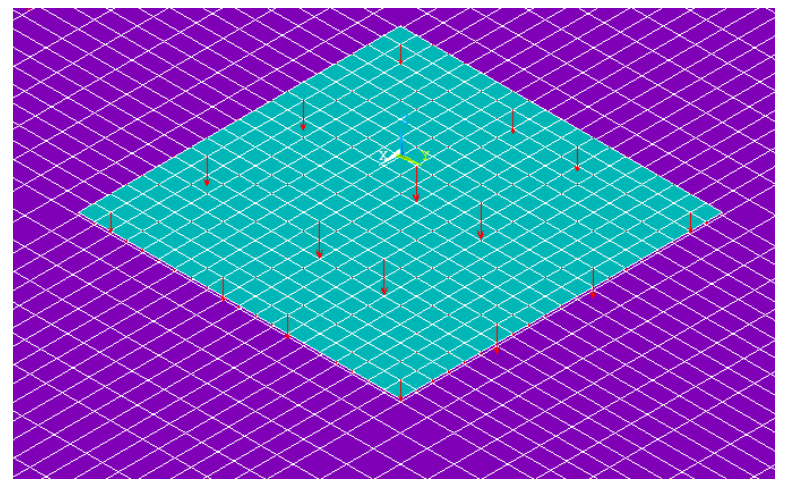

Fig. 1. Detail of loading of the foundation plate.

Structural model was created in the ANSYS software application. The plate was modelled from SHELL element 181, groundmass of elements Solid 185.

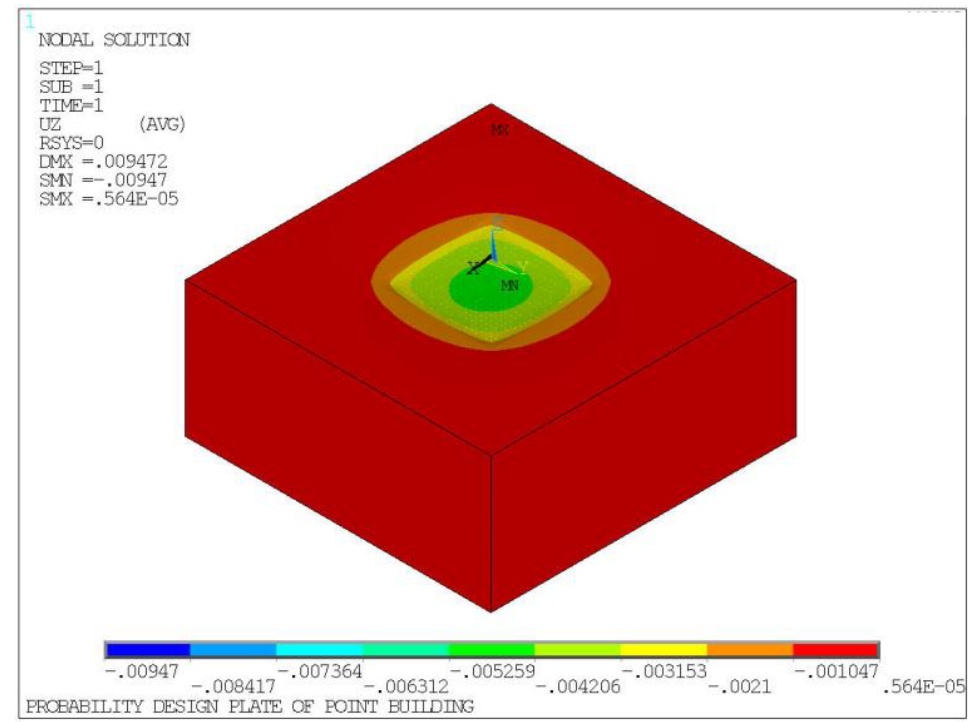

Fig. 2. Vertical deformation of groundmass and foundation plate. 
Contact between the foundation plate and underlying groundmass in ANSYS can be defined in several ways: a) contact point - point b) point - area, c) surface-area. In this case, the contact surface was modelled through bilateral bond by element Contac52 with the stiffness of the surface in contact $6500 \mathrm{kN} / \mathrm{m}$, coefficient of friction 0.5 .

Normal stiffness is calculated from the stiffness of the blinding concrete, which depends on the modulus of elasticity, on the thickness and the area of the priming concrete. The foundation plate is assessed for the second limit state. Maximum deflection from determistic solution was $9.47 \mathrm{~mm}$ in the corner of the foundation plate, (Fig. 2).

\subsection{Probabilistic approach}

When applying probabilistic approach, the individual input values vary according to the tab. 1. Changing the geometrical characteristics of the plate is defined through $H=0.5 \mathrm{~m}$, (plate thickness) and Hvar (change in thickness of the plate). The stiffness plate is determined through the modulus of elasticity $E_{d}=31 \mathrm{GPa}, v=0.2$ and variable factor Evar and Mivar. The load is determined through uniformly distributed load $q=12 \mathrm{kN} / \mathrm{m}$ and forces F from 554 to $988 \mathrm{kN}$ and qvar_and Fvar_variables.

Table 1. Probabilistic model of input variable.

\begin{tabular}{|c|c|c|c|c|}
\hline Material & $\begin{array}{c}\text { Variable } \\
\text { parameter }\end{array}$ & Histogram & $\begin{array}{c}\text { Mean value } \\
\text { or Min. value }\end{array}$ & $\begin{array}{c}\text { Stand. Dev. } \\
\text { or Max.value }\end{array}$ \\
\hline $\begin{array}{c}\text { Concrete } \\
\text { plate }\end{array}$ & EVAR_D & Gaus & 1 & 0.05 \\
\hline & MIVAR_ & Gaus & 1 & 0.05 \\
\hline & HVAR_ & Unif & 0.99 & 1.01 \\
\hline Soil & EVAR_P & Gaus & 1 & 0.05 \\
\hline & MIVAR & Gaus & 1 & 0.05 \\
\hline Load & QVAR & Log1 & 1 & 0.1 \\
\hline & FVAR & Log1 & 1 & 0.1 \\
\hline
\end{tabular}
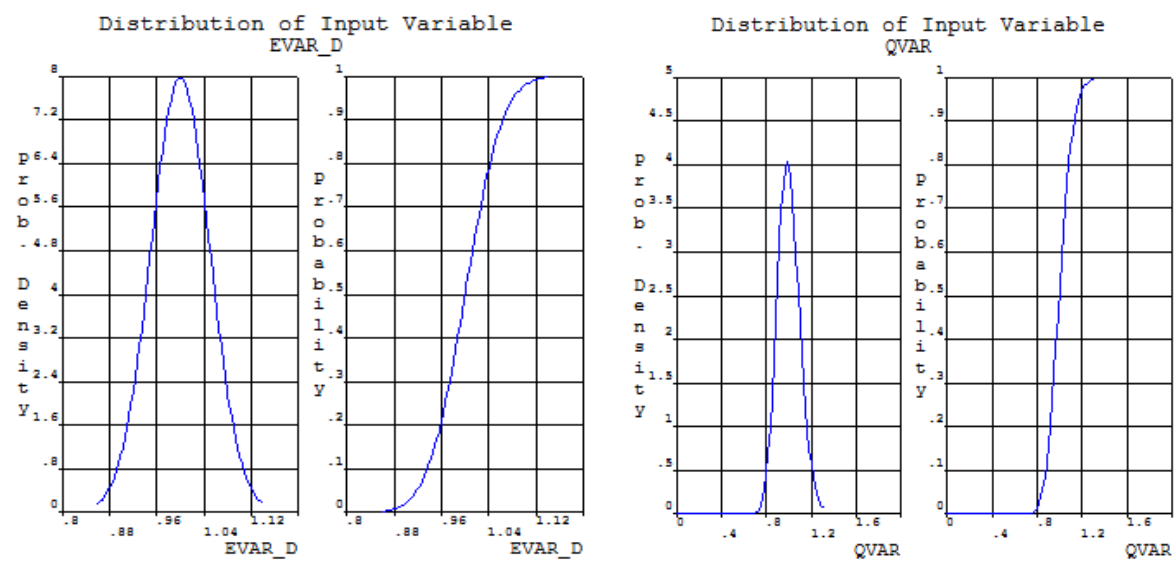

Fig. 3. PDF and CDF of Input Random Variable EVAR_D and QVAR. 
The probability density functions - PDF and cumulative distribution functions- CDF of some input random variables are shown in Fig. 3 to Fig. 4.
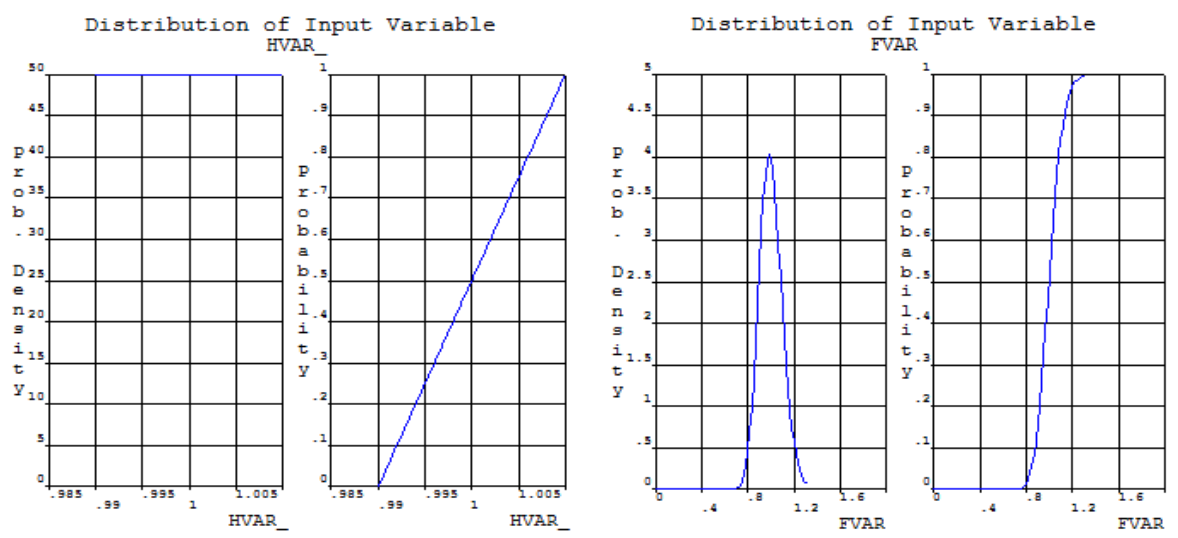

Fig. 4. $P D F$ and CDF of Input Random Variable HVAR_and FVAR.

During a probabilistic analysis, ANSYS executes multiple analysis loops to compute the random output parameters as a function of the set of random input variables. Histogram of ouput random variable PRIEH is shown in the Fig. 5.

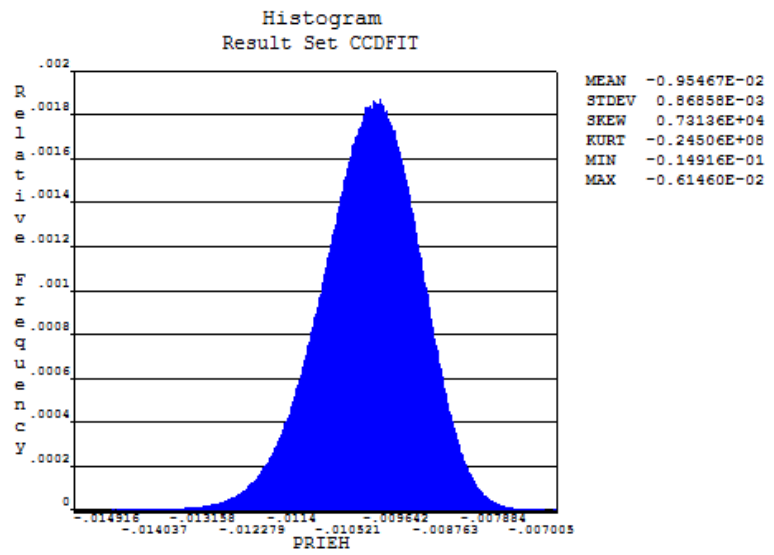

Fig. 5. Histogram of ouput random variable PRIEH.

Resulting from variability of input quantity, 45 simulations on the base of RSM method were realized. The probability of exceeding the limit deflection of plate structures was calculated using 5 million Monte Carlo simulations for 45 simulations of approximation method RSM on the structural FEM model. The probability that PRIEH is smaller than $-1.1 \mathrm{~mm}$ is $5.456 \mathrm{e}-2$. The probability is interpolated between:

PRIEH=-1.1000002 which has rank 272800 out of 5000000 samples,

PRIEH=-1.0999997 which has rank 272801 out of 5000000 samples.

The evaluation of the probabilistic sensitivities is based on the correlation coefficients between all random input variables and a particular random output parameter. Either Spearman rank order correlation coefficients or Pearson linear correlation coefficients may be used based on user's specifications. To plot the sensitivities of a certain random output parameter, the random input variables are separated into two groups: those that are significant (important) and those that are insignificant (not important) for the random 
output parameter. The sensitivity plots will only include the significant random input variables. The dominant impact to reliability of foundation displacement plate has the input parameter FVAR and QVAR (Fig.6).

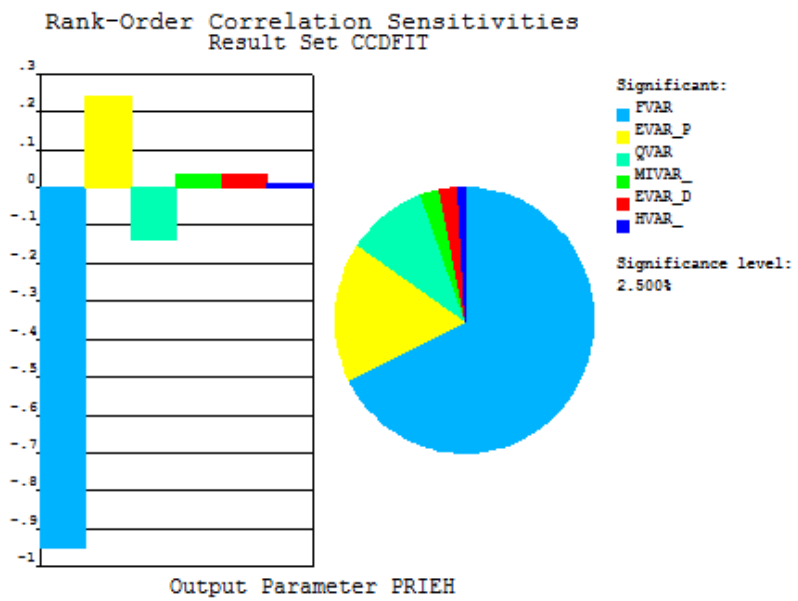

Fig. 6. Sensitivity result of ouput random variable PRIEH.

\section{Conclusion}

This article presented the static analysis of the residential building of point type rested on an elastic half-space, based on a deterministic and probabilistic analysis. Maximum deflection in the foundation gap obtained from deterministic analysis was $9.47 \mathrm{~mm}$. The uncertainties at the level loads, geometry and material characteristics of the calculation model and numerical methods have been taken into account in the Monte Carlo simulation method based on the RSM. The probability of failure of the foundation plate in the ultimate deflection in the foundation gap is $5.456 \mathrm{e}-2$ for maximum allowed deflection of $11 \mathrm{~mm}$.

This contribution is the result of the research supported by the grant from VEGA Slovak Grant Agency Project No. 1/0544/15.

\section{References}

1. M. J. Tomlinson, Foundation Design and Construction (Pearson Education Ltd, England, 2001)

2. K. Kotrasova, E. Kormanikova, A case study on seismic behavior of rectangular tanks considering fluid - Structure interaction, International Journal of Mechanics 10, (2016)

3. P. Marek, J. Brozzetti, M. Gustav, Probabilistic Assessment of Structures Using Monte Carlo Simulation Background, Exercises and Software, ITAM CAS, Prague, Czech Republic, (2003)

4. Martin Krejsa and Juraj Kralik, Probabilistic Computational Methods in Structural Failure Analysis Multiscale Modelling 6: 1550006 DOI:http://dx.doi.org/10.1142/ S17 56973715500067, (2015) 